\title{
Corrigendum
}

\section{Corrigendum to "Risk Assessment of Oxygen Lance Burning Loss Using Bow-Tie Analysis Based on Fuzzy Theory"}

\author{
Jishuo Li (D), Kaili Xu (D), Bingjie Fan, and Liyan Geng \\ School of Resources and Civil Engineering, Northeastern University, Shenyang, China \\ Correspondence should be addressed to Kaili Xu; xkl_safety@163.com \\ Received 14 October 2020; Accepted 14 October 2020; Published 9 November 2020 \\ Copyright (c) 2020 Jishuo Li et al. This is an open access article distributed under the Creative Commons Attribution License, \\ which permits unrestricted use, distribution, and reproduction in any medium, provided the original work is properly cited.
}

In the article titled "Risk Assessment of Oxygen Lance Burning Loss Using Bow-Tie Analysis Based on Fuzzy Theory" [1], there was a spell error in the first author's name in the author list, where "Jishuoli Li" should read "Jishuo Li".

The correct name is shown above.

\section{References}

[1] J. Li, K. Xu, B. Fan, and L. Geng, "Risk assessment of oxygen lance burning loss using bow-tie analysis based on fuzzy theory," Mathematical Problems in Engineering, vol. 2020, Article ID 7172184, 12 pages, 2020. 